\title{
Correction to: Construction of a Pichia pastoris strain efficiently producing recombinant human granulocyte-colony stimulating factor (rhG-CSF) and study of its biological activity on bone marrow cells
}

\author{
M. B. Pykhtina ${ }^{1} \cdot$ V. P. Romanov ${ }^{1} \cdot$ S. M. Miroshnichenko ${ }^{1,2} \cdot$ A. B. Beklemishev $^{1}$ (D)
}

Published online: 18 February 2020

๑) Springer Nature B.V. 2020

\section{Correction to: Molecular Biology Reports (2020) 47:607-620 https://doi.org/10.1007/s1 1033-019-05169-9}

The original publication has been updated. The acknowledgment was omitted from the original article and is published below.
Acknowledgement Authors gratefully acknowledge the financial support of the Russian Science Foundation (Grant No. 18-75-10057) for sponsoring this research.

Publisher's Note Springer Nature remains neutral with regard to jurisdictional claims in published maps and institutional affiliations.

The original article can be found online at https://doi.org/10.1007/ s11033-019-05169-9.

A. B. Beklemishev beklem@niibch.ru

1 Institute of Biochemistry, FRC FTM, 2, Timakov str., Novosibirsk, Russian Federation 630117

2 Institute of Clinical and Experimental LymphologyBranch of the ICG SB RAS, 2, Timakov str., Novosibirsk, Russian Federation 630060 